\title{
Estudo epidemiológico das lentiviroses de pequenos ruminantes na Mesorregião do Oeste Maranhense, Brasil
}

\author{
Patrick Assunção Mourão ${ }^{1}$, Lyah Lamark ${ }^{1}$, Michele Moreira Martins de Oliveira ${ }^{2 *}$, Ana \\ Lucia Abreu Silva ${ }^{3}$ \\ ${ }^{l}$ Médicos Veterinários. \\ ${ }^{2}$ Professora da Universidade CEUMA campus Imperatriz - Avenida Barão do Rio Branco, Qda. 12, $n^{o} 100$ - Maranhão \\ Novo. CEP 65.903-093, Imperatriz - MA.. \\ ${ }^{3}$ Professora Adjunto IV da Universidade Estadual do Maranhão (UEMA). \\ *Autor para correspondência,.E-mail: michele.martins@ceuma.br
}

\begin{abstract}
RESUMO. O presente estudo avaliou os perfis sanitários e epidemiológicos das Lentiviroses de pequenos ruminantes (LVPR) na Mesorregião do Oeste Maranhense, microrregião de Imperatriz. Foram aplicados questionários em 57 propriedades de 14 municípios da região. Também foram colhidas 710 amostras de sangue para realização de testes sorológicos. Os resultados mostraram que as condições sanitárias dos rebanhos são precárias e que as doenças mais comuns foram: míases $(78,9 \%)$ dos rebanhos, linfadenite caseosa $(59,6 \%)$, pododermatite $(47,4 \%)$, aborto $(43,9 \%)$ e mastite $(31,6 \%)$. O teste sorológico revelou que a prevalência independente da espécie testada para Lentiviroses foi de 7,5\% (53/710), não diferindo entre si: 7,5\% (39/481) dos ovinos e 7,4\% (14/176) dos caprinos. Em relação aos municípios observou-se que 12 dos 14 municípios avaliados apresentam animais positivos para LVPR, o que caracteriza o vírus circulante nas propriedades avaliadas e 7 destes municípios apresentaram entre $8 \%$ e $15 \%$ de animais positivos. A técnica de cultivo de leucócitos com posterior co-cultivo foi eficazes no isolamento do vírus, cujas amostras positivas apresentaram formação de sincícios e alterações morfológicas características da patologia.
\end{abstract}

Palavras chave: Lentiviroses, epidemiologia, prevalência, práticas zoosanitária

\section{Epidemiologic study of Lentiviruses in small ruminants from West Mesoregion in Marahão, Brazil}

\begin{abstract}
This study aimed to evaluate the sanitary and epidemiological profiles of small ruminants Lentiviruses (LVPR) from Meso West Maranhense in Imperatriz Micro region, Maranhão, Brazil. Questionnaires were applied in 57 rural properties of this region, in a total of 14 Municipalities. Beside that, 710 blood samples were collected for serologic testing. The results showed that sanitary conditions are poor and the most frequent disease were: myiasis $(78.9 \%)$, caseous lymphadenitis $(59.6 \%)$, footpad dermatitis $(47.4 \%)$, abortion (43.9\%), mastitis (31.6\%). Serologic testing revealed that the general prevalence of Lentiviruses was $7.5 \%$ (53/710) did not differ from each other: $7.5 \%$ (39/481) of sheep and 7.4\% (14/176) goats. Regarding the municipalities it was observed that 12 of the 14 municipalities assessed presented positive animals for LVPR, characterizing the circulating viruses in this one. Among even of these Municipalities the prevalence ranged from $8 \%$ to $15 \%$.
\end{abstract}

Keywords: Lentiviruses, epidemiology, prevalence, zoosanitary practices

\section{Introdução}

No Estado do Maranhão e na Microrregião de Imperatriz, apesar de apresentar condições geoclimáticas favoráveis à criação de caprinos e ovinos o número destas criações vem diminuindo devido à carência de um manejo higiênicosanitário eficiente e pouca aplicação de 
tecnologias reprodutivas, o que favorece o surgimento e a disseminação de doenças infecciosas, dentre elas as lentiviroses de pequenos ruminantes (LVPR).

Os LVPR são agrupados em cinco grupos filogenéticos, dos quais os principais estão representados pelos protótipos vírus Maedi-Visna (MVV) e Artrite-encefalite Caprina (CAEV) (Alves \& Pinheiro, 1997, Pittavino et al., 2014). Estes vírus podem acometer pequenos ruminantes de todas as idades, sexo e raça, levando a uma queda acentuada na produção e, consequente comprometimento da rentabilidade da atividade (Peterhans et al., 2004).

O reservatório e a fonte de infecção de LVPR são os animais infectados que transmitem o agente por meio de secreções e excreções ricas em células contaminadas (Lamara et al., 2013). A transmissão dos LVPR pode ocorrer verticalmente pela ingestão de colostro e leite contaminados (Herrmann-Hoesing, 2010, Blacklaws et al., 2004) ou por meio da transmissão intra-uterina (Brodie et al., 1994), a transmissão horizontal requer contato direto e prolongado entre os animais e pode ocorrer ainda pelas fômites contaminados (Konishi et al., 2011). Levanta-se também hipótese de transmissão pela monta natural ou inseminação artificial (Andrioli et al., 2006).

Para o controle de LVPR, o diagnóstico é uma ferramenta importante, uma vez que as decisões em relação ao rebanho serão tomadas com base em seus resultados. A Organização Mundial para Saúde Animal (OIE) preconiza o uso dos testes sorológicos de imunodifusão em gel de agarose (IDGA) e Immuno absorbentassay (ELISA) para diagnóstico de LVPR. No Brasil, o Plano Nacional de Vigilância e Controle de Lentiviroses de Pequenos Ruminantes (PNVCLVPR) preconiza como diagnóstico de rotina a IDGA, devendo ser realizado western blotting (WB) e a reação em cadeia de polimerase (PCR) em casos duvidosos.

Este trabalho teve por objetivo realizar inquérito soro epidemiológico no rebanho de ovinos e caprinos criados na Mesorregião Oeste do Estado do Maranhão.

\section{Material e Métodos}

O presente estudo foi desenvolvido em propriedades criadoras de caprinos e ovinos, da Mesorregião do Oeste Maranhense, Microrregião de Imperatriz, em quatorze municípios:
Açailândia, Amarante do Maranhão, Buritirana, Cidelândia, Davinópolis, Governador Edison Lobão, Imperatriz, Itinga do Maranhão, João Lisboa, Lajeado Novo, Montes Altos, Ribamar Fiquene, São Francisco do Brejão e Senador La Roque.

Visando descrever a forma de produção e inferir sobre o perfil sanitário dos estabelecimentos produtores de caprinos e ovinos foi realizado inquérito epidemiológico com aplicação de um questionário adaptado de Tinôco (1983) levando-se em consideração algumas características de produção e manejo das propriedades.

O número mínimo de amostras de caprinos e ovinos foi determinado utilizando-se fórmula descrita por Thrusfield (2004) adotando uma prevalência esperada de $50 \%$ uma vez que não existem relatos da prevalência de LVPR na microrregião de Imperatriz, intervalo de confiança de $95 \%$ e um erro amostral de $( \pm$ 5\%),obtendo-se assim um total de 710 amostras, sendo testados 10 animais por rebanho, estratificados segundo a composição aproximada dos rebanhos (Souza Neto, 1987) com um reprodutor, seis matrizes e três fêmeas nulíparas (entre 6 e 12 meses), selecionados aleatoriamente.

Para o estudo sorológico foi coletado sangue por venopunção jugular utilizando tubo tipo vaccutainer sem anticoagulante para obtenção de soro. Para detecção dos anticorpos anti-LVPR, o soro de cada animal foi submetido ao teste de IDGA, conforme protocolo descrito por Abreu et al. (1998) utilizando o kit antígeno CAEV.

Nos inquéritos soro epidemiológicos foram calculadas as prevalências com os respectivos desvios padrões. A associação entre o manejo adotado nas criações e a ocorrência das lentiviroses foi testada utilizando o teste de Quiquadrado $\left(\chi^{2}\right)$, sendo ainda calculada a razão de odds (OR) com intervalo de confiança de $95 \%$ utilizando-se programa EPI-INFO (Dean et al., 1990).

\section{Resultados e discussão}

Foram visitadas 57 propriedades distribuídas nos 14 municípios da Microrregião de Imperatriz. $\mathrm{O}$ número de animais dos rebanhos variou entre 12 e 3000 cabeças, com média de 49 animais por propriedade. Foi constatado que os ovinos correspondem 73,2\% (520/710) do rebanho e os 
caprinos representam 26,8\% (190/710) dos animais analisados. A frequência de animais positivos na técnica de IDGA para LVPR foi de 7,5\% (53/710). Em relação à espécie acometida observou-se prevalência semelhante entre as espécies com 7,5\% (39/520) de ovinos e 7,4\% (14/190) de caprinos soropositivos. As fêmeas apresentaram prevalência de anticorpos antiLVPR de $8,1 \%$ (48/591) e os machos de 7,0\% $(5 / 66)$ (Tabela 1).
Estudo realizado por Teixeira (2012) mostra a permanência e circulação das Lentiviroses de pequenos ruminantes nas regiões leste, centro e norte do estado do Maranhão, com prevalência em caprinos e ovinos de $2,8 \%$ e $0,7 \%$, respectivamente. Os dados apresentados neste estudo reforçam a necessidade da adoção de medidas de controle para esta doença, visto que demonstrou prevalência ainda maior do que a observada por Teixeira (2012).

Tabela 1. Resultado do teste de Imunodifusão em Gel de Agarose (IDGA) para Lentivírus de Pequenos Ruminantes (LVPR) de 710 animais em relação à espécie e a categoria animal

\begin{tabular}{cccccc}
\hline & & LVPR + & LVPR & $\mathrm{n}(\%)$ & $\mathrm{P}$ \\
\hline Espécie & Ovina & 39 & 481 & $520(73,2 \%)$ & 0,9185 \\
& Caprina & 14 & 176 & $190(26,8 \%)$ & 0,4469 \\
\hline Categoria & Matriz & 34 & 392 & $426(60,0 \%)$ & \\
Animal & Fêmea Jovem & 14 & 199 & $213(30,0 \%)$ & \\
& Reprodutor & 5 & 66 & $71(10,0 \%)$ & \\
\hline Total & & 53 & 657 & $710(100 \%)$ & \\
\hline
\end{tabular}

A Tabela 2 mostra prevalência de anticorpos anti-Lentivírus em pequenos ruminantes, por município da Microrregião de Imperatriz.

Das propriedades visitadas, se o regime de criação extensivo era adotado em 54,4\% (31/57) e semi intensivo em 45,6\% (26/57), não foi verificado sistema intensivo de criação em nenhuma das propriedades visitadas. Não foi verificada diferença estatística na positividade pelo teste de IDGA entre o sistema extensivo e semi intensivo (Prova Exata de Fischer, $\chi^{2}, \mathrm{P}>$ $0,05)$. Os dados quanto ao regime de criação são semelhantes aos encontrados em três municípios no interior da Bahia (Tinôco, 1983), bem como no trabalho realizado nas regiões centro, leste e norte do estado do Maranhão (Teixeira, 2012). O regime de criação encontrado reflete o nível sociocultural dos criadores de caprinos.

Tabela 2. Total de propriedades, soros amostrados e testados pela Imunodifusão em Gel de Agarose (IDGA) e prevalência de anticorpos anti-lentivírus em pequenos ruminantes, por município da microrregião de Imperatriz

\begin{tabular}{|c|c|c|c|}
\hline Município & $\begin{array}{c}\text { Propriedades } \\
\mathrm{n}\end{array}$ & $\begin{array}{c}\text { Soros amostrados } \\
\mathrm{n}\end{array}$ & $\begin{array}{c}\text { Soros positivos } \\
\mathrm{n}\left(\mathrm{p}^{*}\right)\end{array}$ \\
\hline Açailândia & 6 & 60 & $5(8,3 \%)$ \\
\hline Amarante & 3 & 60 & $6(10,0 \%)$ \\
\hline Buritirana & 2 & 20 & $3(15,0 \%)$ \\
\hline Cidelândia & 4 & 60 & $6(10,0 \%)$ \\
\hline Davinópolis & 5 & 60 & $3(5,0 \%)$ \\
\hline Gov. Edson Lobão & 4 & 60 & $6(10,0 \%)$ \\
\hline Imperatriz & 3 & 40 & $4(10,0 \%)$ \\
\hline Itinga & 3 & 30 & $8(26,7 \%)$ \\
\hline João Lisboa & 4 & 50 & $2(4,0 \%)$ \\
\hline Lajeado Novo & 5 & 50 & $3(6,0 \%)$ \\
\hline Montes Altos & 5 & 60 & 0 \\
\hline Ribamar Fiquene & 4 & 40 & 0 \\
\hline São Franc. do Brejão & 5 & 60 & $5(8,3 \%)$ \\
\hline Senador La Rocque & 4 & 60 & $1(1,7 \%)$ \\
\hline
\end{tabular}

$* \mathrm{p}=$ prevalência.

Fonte: Trabalho de campo (2012) 
Em relação a origem dos rebanhos estudados cerca de 94,7\% (54/57) advém do estado do Maranhão e uma pequena proporção é originária do estado do Ceará 1,8\% (1/57) e Pernambuco $3,50 \%$ (2/57). Não houve relação entre animais originados dos Estados de Pernambuco e Ceará nos resultados positivos encontrados neste trabalho.

Quanto à aquisição dos reprodutores, 78,9\% dos produtores informaram terem comprado $19,3 \%$ realizam o sistema de troca com outros produtores da mesma região e em $1,8 \%$ saõ utilizados animais emprestados. A participação em exposição de animais foi confirmada em $14,0 \%$ das criações. O trânsito de animais em eventos ou em compra e venda ou troca não resultou em fator estatisticamente significativo na titulação positiva de anticorpos para LVPR neste trabalho $(\mathrm{P}=0,5)$.

Parte dos produtores $(36,4 \%)$ informou que cria os animais apenas para o consumo próprio e que não os vendem porque são de baixo valor zootécnico. Os produtores que criam e esporadicamente à medida que o rebanho cresce, vendem o excedente, descobriram que as criações podem representar uma possibilidade de capital rápido quando necessário.

Quanto à modalidade de criação de caprinos e ovinos separadamente ou associada não se demonstrou diferença estatisticamente significativa em relação à soro positividade dos animais para LVPR neste trabalho $(\mathrm{P}=0,2600)$. Contudo, nas 57 propriedades que foram visitadas, $24,6 \%$ (20/57) criam caprinos e ovinos juntos. Destas, 60\% (12/20) apresentam animais com anticorpos anti-LVPR. Estudos realizados por (Pisoni et al., 2007, Alves \& Pinheiro, 1997, Martínez-Navalón et al., 2013) tem demonstrado as características e possibilidades de transmissão inter espécies dos LVPR. Gomez-Lucia et al. (2013) descreve ainda a identificação de novos subtipos de LVPR e subsequente infecção cruzada inter espécies, inclusive com adaptações à animais selvagens.

As LVPRs identificadas em animais selvagens demostram adaptação e emergência destes vírus a novos hospedeiros o que pode pressupor novas propriedades biopatológicas capazes de afetar novos hospedeiros além de ruminantes domésticos (Gomez-Lucia et al., 2013). Conforme caracterização molecular parcial do gene gag, Marchesin et al. (1997) sugeriram similaridade genética entre o vírus da CAEV e
Maedi-Visna, o que levantou a hipótese da transmissão inter espécie. No Brasil estudos filogenéticos dos genes Pole Tat de amostras de vírus caprino revelaram mais similaridade ao vírus Maedi-Visna K1514 (Abreu et al., 1998, Pisoni et al., 2007).

Os rebanhos de caprinos e ovinos da microrregião de Imperatriz apresentaram os seguintes problemas de ordem sanitária: miíases (78,9\%), linfadenite caceosa (59,6\%), pododermatites $(47,4 \%)$, aborto $(43,9 \%)$, mastites $(31,6 \%)$, diarréias $(29,8 \%)$, artrite $(28,1 \%)$, cerato conjuntivite $(24,6 \%)$, pneumonia $(22,8 \%)$, afecções do sistema nervoso $(22,8 \%)$, ectoparasitas $(21,1 \%)$ e ectima contagioso $(14,0 \%)$.

Quanto às práticas zoosanitárias, observa-se que o aleitamento artificial é realizado por $66,7 \%$ (38/57) das propriedades, contudo é necessário ressaltar que a prática é feita quando há rejeição das crias pelas mães, e não como uma prática de controle de doenças advindas do aleitamento.

Com relação à frequência das práticas zoosanitárias mais adotadas nas 57 propriedades estudadas, alcançou-se os seguintes resultados: Separação jovens e adultos, 7 (12,3\%); quarentena, 13 (22,8\%); piquete maternidade 16 $(28,1 \%)$; corte e desinfecção de umbigo, 22 $(38,6 \%)$; calendário profilático, $25(43,8 \%)$; esterilização de materiais, 30 (52,6\%); utiliza descartável, 33 (57,9\%); aleitamento artificial, 38 $(66,7 \%)$ e vermifugação, $52(91,2 \%)$.

A semelhança do que ocorre em outros estados, a vermifugação é uma das poucas medidas de controle sanitário que maioria das propriedades adota. Oliver et al. (1985) descrevem que $74 \%, 75 \%, 93 \%$ e $96 \%$ dos criatórios pesquisados nos estados do Ceará, Piauí, Bahia e Pernambuco, respectivamente realizam a vermifugação em seus criatórios. Caldas et al. (1989) relatam que no Nordeste da Bahia, 36,5\% dos criadores realizavam vermifugação dos rebanhos. Em relação à vacinação, esses mesmos autores verificaram que somente $8,7 \%$ dos criadores de caprinos realizavam vacinação contra raiva/aftosa, $0,4 \%$ contra botulismo/carbúnculo e $0,1 \%$ contra linfadenite caseosa.

O baixo índice de utilização das práticas de manejo sanitário por parte dos criatórios estudados contribui, sem dúvida, para a manutenção dos altos níveis de mortalidade e de 
morbidade observados. Isso se reflete alta frequência de doenças como linfoadenite, por exemplo, entre os animais estudados. Tais doenças também foram descritas por Teixeira (2012). No Maranhão, a enfermidade está disseminada desde a década de 90 , alcançando índices de prevalência de 50,6\% em animais de distintos padrões raciais (Alves \& Pinheiro, 1997).

\section{Conclusão}

Dentre os quatorzes municípios avaliados, doze apresentam animais positivos para LVPR, o que caracteriza $o$ vírus circulante nas propriedades avaliadas. Verificou-se que problemas como, linfadenite, mamite, pneumonia e artrite acometem a maioria dos rebanhos estudados e que as práticas básicas de manejo sanitário são negligenciadas pelos produtores. $\mathrm{O}$ gerenciamento da propriedade é inadequado e sua ineficiência impede inclusive a reserva alimentar para o período de escassez. O manejo sanitário dos caprinos e ovinos nesses criatórios é precário. O caprino e ovinocultor da mesorregião oeste do Estado do Maranhão, mesmo sendo um indivíduo alfabetizado e detentor de patrimônio que viabilize a contratação de técnicos especializados não tem acesso à informação pertinente à sua criação, seus rebanhos são pequenos e criados extensivamente em instalações rústicas.

\section{Agradecimentos}

À Fundação de Amparo à Pesquisa e Desenvolvimento Científico do Maranhão FAPEMA pelo financiamento do projeto 00474/11. Ao Professor DSc. Roberto Soares de Castro da UFRPE pelos kits de IDGA.

\section{Referências Bibliográficas}

Abreu, S. R. O., Castro, R. S., Nascimento, S. A. \& Souza, M. G. (1998). Produção de antígeno nucleoprotéico do vírus da artrite-encefalite caprina e comparação com o do vírus MaediVisna para utilização em teste de imunodifusão em ágar gel. Pesquisa Veterinária Brasileira, 18, 57-60.

Alves, F. S. F. \& Pinheiro, R. R. (1997). Presença da artrite encefalite caprina a vírus (CAEV) no estado do Maranhão. Congresso Brasileiro de Medicina Veterinária.

Andrioli, A., Pinheiro, R. R., Olortegui, C. D. C., Gouveia, A. M. G. \& Araujo, S. C. (2006). Desenvolvimento de dot-blot para detecção de anticorpos para o vírus da artrite-encefalite caprina em caprinos. Revista Portuguesa de Ciências Veterinárias, 101, 557-558.

Blacklaws, B. A., Berriatua, E., Torsteinsdottir, S., Watt, N. J., Andrés, D., Klein, D. \& Harkiss, G. D. (2004). Transmission of small ruminant lentiviruses. Veterinary Microbiology, 101, 199-208.

Brodie, S. J., Concha-Bermejillo, A., Koenig, G., Snowder, G. D. \& DeMartini, J. C. (1994). Maternal factors associated with prenatal transmission of ovine lentivirus. Journal of Infectious Diseases, 169, 653-657.

Caldas, E. M., Santana, A. F. \& Caetano, A. L. S. (1989). Estudo da ovinocaprinocultura na região Nordeste do Estado da Bahia. Arquivos da Escola de Veterinária da Universidade Federal da Bahia, 12, 1-96.

Dean, A. G., Dean, J. A., Brendel, K. A. \& Control, C. f. D. (1990). Epi Info, version 5: A word processing, database, and statistics system for epidemiology on microcomputers. US Department of Health and Human Services, Public Health Service, Centers for Disease Control.

Gomez-Lucia, E., Rowe, J., Collar, C. \& Murphy, B. (2013). Diversity of caprine arthritis-encephalitis virus promoters isolated from goat milk and passaged in vitro. The Veterinary Journal, 196, 431-438.

Herrmann-Hoesing, L. M. (2010). Diagnostic assays used to control small ruminant lentiviruses. Journal of Veterinary Diagnostic Investigation, 22, 843-855.

Konishi, M., Nagura, Y., Takei, N., Fujita, M., Hayashi, K., Tsukioka, M., Yamamoto, T., Kameyama, K.-i., Sentsui, H. \& Murakami, K. (2011). Combined eradication strategy for CAE in a dairy goat farm in Japan. Small Ruminant Research, 99, 65-71.

Lamara, A., Fieni, F., Chatagnon, G., Larrat, M., Dubreil, L. \& Chebloune, Y. (2013). Caprine arthritis encephalitis virus (CAEV) replicates productively in cultured epididymal cells from goats. Comparative Immunology, Microbiology and Infectious Diseases, 36, 397-404.

Marchesin, D. M., Moojen, V. \& Ravazzolo, A. P. (1997). Caracterização molecular do gene gag de amostras do vírus da artrite encafalite caprina (CAEV) isoladas de animais 
naturalmente infectados no Rio Grande do Sul, Brasil. Pesquisa Veterinária Brasileira, $18,119-126$

Martínez-Navalón, B., Peris, C., Gómez, E. A., Peris, B., Roche, M. L., Caballero, C., Goyena, E. \& Berriatua, E. (2013). Quantitative estimation of the impact of caprine arthritis encephalitis virus infection on milk production by dairy goats. The Veterinary Journal, 197, 311-317.

Oliver, R., Cathcart, A., McNiven, R., Poole, W. \& Robati, G. (1985). Infection of lambs with caprine arthritis encephalitis virus by feeding milk from infected goats. Veterinary Record, $116,83$.

Peterhans, E., Greenland, T., Badiola, J., Harkiss, G., Bertoni, G., Amorena, B., Eliaszewicz, M., Juste, R. A., Kraßnig, R. \& Lafont, J.-P. (2004). Routes of transmission and consequences of small ruminant lentiviruses (SRLVs) infection and eradication schemes. Veterinary Research, 35, 257-274.

Pisoni, G., Bertoni, G., Puricelli, M., Maccalli, M. \& Moroni, P. (2007). Demonstration of coinfection with and recombination by caprine arthritis-encephalitis virus and maedivisna virus in naturally infected goats. Journal of Virology, 81, 4948-4955.

Pittavino, M., Ferreri, L., Giacobini, M., Bertolotti, L., Rosati, S. \& Venturino, E. (2014). A CAEV epidemiological model for goat breeding. Applied Mathematics and Computation, 227, 156-163.

Souza Neto, J. (1987). Demanda potencial da carne de caprinos e ovinos e perspectivas da oferta 1985/1990. Boletim de Pesquisa, 4, 713.

Teixeira, W. C. (2012). Soroprevalência de lentiviroses de pequenos ruminantes $\mathrm{e}$ caracterização dos rebanhos caprinos e ovinos no estado do Maranhão, Brasil. Animal Science. Universidade Federal Rural de Pernambuco, Recife.

Thrusfield, M. V. (2004). Inquéritos. Epidemiologia Veterinária, 2, 223-247.

Tinôco, A. L. A. (1983). Diagnóstico de situação da ovino/caprinocultura em três municípios do sertão baiano-Euclides da Cunha, Quijingue, Monte Santo-Bahia, 1981/1982. Seminário (Especialização Medicina Veterinária Preventiva). Escola de Veterinária da Universidade Federal de Minas Gerais, Belo Horizonte.

Recebido em Março 23, 2016

Aceito em Abril 20, 2016

License information: This is an open-access article distributed under the terms of the Creative Commons Attribution License, which permits unrestricted use, distribution, and reproduction in any medium, provided the original work is properly cited. 